\title{
Association between college health services and contraceptive use among female students at five colleges in Wuhan, China: a cross-sectional study
}

\author{
Lu Long ${ }^{1+}$, Zhenhua Chen ${ }^{2+}$, Yun Shi ${ }^{3}$, Sheng Wei ${ }^{3}$, Shaofa $\mathrm{Nie}^{3^{*}}$ and Yi Liü
}

\begin{abstract}
Background: College students have a high incidence of unplanned pregnancies in China, which has highly raised public attention. As such, numerous reproductive health services are provided to college students. This study examined whether health services in college lead to contraceptive use among female college students in heterosexual relationships.

Methods: A self-administered questionnaire survey with cross-sectional design was administered among female students in four colleges in Wuhan, China to identify health service factors associated with contraceptive use in the past 6 months.

Results: The analysis revealed that younger female students had lower odds of contraception use, whereas students who reported availability of health-related web sites were more likely to use contraceptives. Female students who reported that contraceptives and birth control counselling were accessible from college health services had greater odds of contraceptive usage. Finally, provision of contraceptives and birth control counselling from school were associated with greater odds of contraceptive use.

Conclusions: Contraceptive-related health services play an important role in reducing unintended pregnancies by directly addressing the contraceptive needs of female students. Programs that provide targeted services may help to reduce high rates of unexpected pregnancies among female students in China.
\end{abstract}

Keywords: Health service, Contraceptive use, Females, College students

\section{Background}

In a context of dramatic social change, social and economic development, and the advancement of the digital age, attitudes toward sexuality are becoming much more open, particularly among college students aged 15 to 23 [1]. Research on sexuality and the sexual behavior of Chinese college students over the last decade has shown that, among female students with sexual experience, over $10 \%$ had experienced an unexpected pregnancy $[2,3]$. A

\footnotetext{
* Correspondence: shaofanie5@gmail.com; hxliuyi@163.com

${ }^{\dagger}$ Equal contributors

${ }^{3}$ Tongji Medical College, Huazhong University of Science and Technology, Wuhan, China

'West China School of Public Health, Sichuan University, Chengdu, China

Full list of author information is available at the end of the article
}

significant amount of research has been conducted on female involvement in reproductive health decision making, especially for young women $[4,5]$. Women's lives are strongly impacted by pregnancy, and they can improve their sexual health outcomes through the consistent use of contraception to reduce the chances of unintended pregnancy and therefore prevent the need for abortion $[5,6]$.

The media has become one of the most important sources of reproductive health information among Chinese youth, especially college students [7]. In fact, several studies in China have shown that students' main source of knowledge on sex and reproduction is the media, including books, magazines and other periodicals, movies, and television [7, 8]. Education from both school and family is the most basic tool to increase young

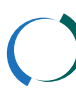

Biomed Central (c) 2016 The Author(s). Open Access This article is distributed under the terms of the Creative Commons Attribution 4.0 International License (http://creativecommons.org/licenses/by/4.0/), which permits unrestricted use, distribution, and reproduction in any medium, provided you give appropriate credit to the original author(s) and the source, provide a link to the Creative Commons license, and indicate if changes were made. The Creative Commons Public Domain Dedication waiver (http://creativecommons.org/publicdomain/zero/1.0/) applies to the data made available in this article, unless otherwise stated. 
people's knowledge of and capacity for protecting themselves, but it is largely ignored by teachers and parents because of the cultural norms inhibiting the discussion of sexual matters [9]. A recent study of Internet-based sex education programs has suggested that the Internet is a feasible and effective way of influencing college students' sexual behavior [9]. In addition, health services, including providing free contraceptives and counseling at college and university student health centers, have been linked to increased contraceptive use and consistency of use among female students $[10,11]$. The lack of counseling designed to help improve the results of sexual activity prevents many young people from seeking contraceptives [12-14]. In addition, a recent study suggested that more convenient access to services and contraceptives may be an important intervention to increase contraceptive use [15].

A better understanding of the influences on contraceptive use among female students will help to inform pregnancy prevention efforts. In this study, we expanded on previous research to assess the association between the availability of health services and contraceptive use and consistency of use. We believe that our study will contribute to a better understanding of the kind of reproductive health services that are currently needed and guide interventions and public policies aimed at improving health services and reducing the number of unintended pregnancies.

\section{Methods}

\section{Study context}

This study was conducted in Wuhan Municipality, Hubei Province, from April to June in 2013. The sample for the study was drawn using multistage stratified cluster sampling. The primary sampling units were colleges in comprehensive universities, as defined by the college entrance examination brochures. The five selected colleges (clusters) were of approximately equal size in terms of area and population. In the second stage of sampling, we selected half of the classes in the first to fourth years in every selected college by using simple random sampling. We attempted to recruit all female students in these classes. Only females who had been sexually active in the past 6 months and who responded to a question about contraceptive use were included in the analysis. Ultimately, our analytic sample included 915 female students.

\section{Data collection instrument, recruitment, and data collection}

Students were asked to complete a questionnaire independently in the classroom after a trained staff member provided a brief introduction and instructions. The questionnaire was anonymous and required approximately
10 min to complete. The included questions were developed based on past research and revised using qualitative methods including in-depth interviews with 20 students (four women from each selected college) and five focus group meetings (one at each selected college). The questionnaire was then pilot tested in a group of 50 randomly selected female students in a college. The reliability of the questionnaire was evaluated by comparing the results from two administrations of the same survey to the same 110 female college students with a 2-week interval. More than two-thirds of questions had Kappa statistics over 0.4 (all $p<0.05$ ). Cronbach's alpha coefficient, which was calculated to determine the internal consistency of the scales in the questionnaire, ranged from 0.73 to 0.86 . Principal components analysis suggested a good fit and confirmed the internal design of the questionnaire.

Data on contraceptive use were collected through responses to the following statement: "Please check the boxes adjacent to any form of contraception/protection you or your partner are currently using." A variety of contraceptive options were listed (Table 1). Respondents were given the option of selecting "none" or "other," in which case they were asked to specify their current method in a text box.

\section{Dependent variables}

Our dependent variables were derived from two questions regarding contraceptive use in the past 6 months: "During the past 6 months, have you used contraception to prevent pregnancy or sexually transmitted diseases during most sexual events?" and "How often when you and your partner had sex together did you use contraceptives during the past 6 months?" Using these questions, we constructed two dichotomous dependent variables. The first compared female students who had used contraception in every instance with those who had not used contraception consistently. The second compared students who had frequently used contraception with those who had used contraception with a low frequency.

\section{Explanatory variables}

We measured three individual characteristics: age, relationship type (steady vs casual), and year in college. A casual partner was one with whom a respondent reported to have had a single encounter. A steady partner was defined as a sexual partner with who a study participant met on a regular basis.

Several developments concerning contraceptive use among college students have occurred in China in recent years, including colleges' increasing provision of reproductive health publications and development of reproductive health websites for college students $[3,7]$. For that reason we wished to assess whether the provision of health-related 
Table 1 Distribution of dependent variables and individual, enabling resources, health services and contraception/safer sex options utilized among sexually active female students

\begin{tabular}{|c|c|c|}
\hline \multirow[t]{2}{*}{ Characteristic } & \multicolumn{2}{|c|}{ Sexually active females } \\
\hline & $\mathrm{n}$ & $\%$ \\
\hline Total & 915 & 100 \\
\hline \multicolumn{3}{|l|}{ Fully consistent contraceptive use } \\
\hline Yes & 318 & 34.7 \\
\hline No & 597 & 65.3 \\
\hline \multicolumn{3}{|l|}{ Frequency of contraceptive use } \\
\hline High & 670 & 73.2 \\
\hline low & 245 & 26.8 \\
\hline Age & $15-24^{a}$ & $20.5 \pm 2.54^{b}$ \\
\hline \multicolumn{3}{|l|}{ Relationship status } \\
\hline Steady & 801 & 87.5 \\
\hline Casual & 114 & 12.5 \\
\hline \multicolumn{3}{|l|}{ Grade } \\
\hline Senior & 534 & 58.4 \\
\hline Junior & 382 & 41.7 \\
\hline \multicolumn{3}{|l|}{ health services ${ }^{c}$} \\
\hline Provision of health related publications & 544 & 59.5 \\
\hline Availability of designed Web site & 633 & 72.8 \\
\hline school education & 254 & 27.8 \\
\hline Provision of contraceptives & 218 & 23.8 \\
\hline Provision of birth control counseling & 135 & 14.7 \\
\hline Convenient getting contraceptives & 118 & 12.9 \\
\hline Convenient getting birth control counseling & 87 & 9.5 \\
\hline Convenient getting birth control counseling & 87 & 9.5 \\
\hline \multicolumn{3}{|l|}{ Contraception/safer sex options ${ }^{c}$} \\
\hline Condoms & 535 & 61.5 \\
\hline Oral female contraceptives & 233 & 26.8 \\
\hline Rhythm method & 217 & 24.9 \\
\hline Emergency contraception & 109 & 12.5 \\
\hline Contraceptive patches & 61 & 7.5 \\
\hline Spermicides & 43 & 4.9 \\
\hline others & 9 & 1.0 \\
\hline
\end{tabular}

arange

${ }^{b}$ mean \pm SD

cMultiple choice

publications in college and availability of websites were a factor associated with the contraceptive use of college students. The survey assessed whether respondents had access to reproductive health information at their colleges from publications including books, newspapers, websites, and school education. Two response choices (yes and no) were provided for each item. In terms of health services, we measured whether health-related publications (i.e., books and newspapers) and health-related websites were provided in the college and whether health-related courses were offered at the college.

We also measured whether the school provided contraceptives or birth control counseling to female students. Birth control counseling referred to counseling designed to help reduce pressure for college students to become sexually active and improve the results of sexual activity. Additionally, we assessed whether contraceptives and birth control counseling were considered to be convenient to acquire in each college.

\section{Data analysis and ethical clearance}

Data were processed using EpiData version 3.1 and analyzed using Stata version 12.0 software (StataCorp LP, College station, TX: USA). Frequencies and means were calculated for the measured demographic characteristics. Univariate logistic regression models were computed to examine the level of association between individual characteristics, available resources, health services, and contraceptive use. Nominal level independent variables with more than two categories were transformed into dummy variables and assigned reference categories. Variables significant in the univariate analyses $(p<0.05)$ were entered in a multivariate logistic regression model. In the logistic regression model, we adopted the "Enter" method to achieve a final model. The standard for the variable inclusion was based on SLENTRY $=0.05$, and the exclusion standard was SLSTAY $=0.10$.

The researchers obtained consent from all participants involved in the study. The study was approved by the Research Ethics Committee of Tongji Medical College at Huazhong University of Science and Technology in Wuhan, China. We provided detailed information on the study to the eligible college students and included only those who consented to participate. We obtained written informed consent from all respondents.

\section{Results \\ Sample demographics}

As is shown in Fig. 1, of the 9325 possible research participants, 9052 responded validly, giving a final response rate of $97.1 \%$. Women were considered to be sexually active if they reported having had sex with a male partner in the past 6 months. Of the 9052 respondents, $10.1 \%(915 / 9052)$ of the women reported being sexually active in the past 6 months.

As shown in Table 1, more than one-third of the sexually active women in the sample reported consistent contraceptive use during the recent most recent sexual intercourse event. The overall sample $(N=915)$ of sexually active female college students averaged nearly 21 years of age (mean $=20.5, \mathrm{SD}=2.54$ ). The age range was $15-24$. Most of these women had a steady partner $(87.5 \%)$. More than two-thirds $(72.8 \%)$ of sexually active females reported that 


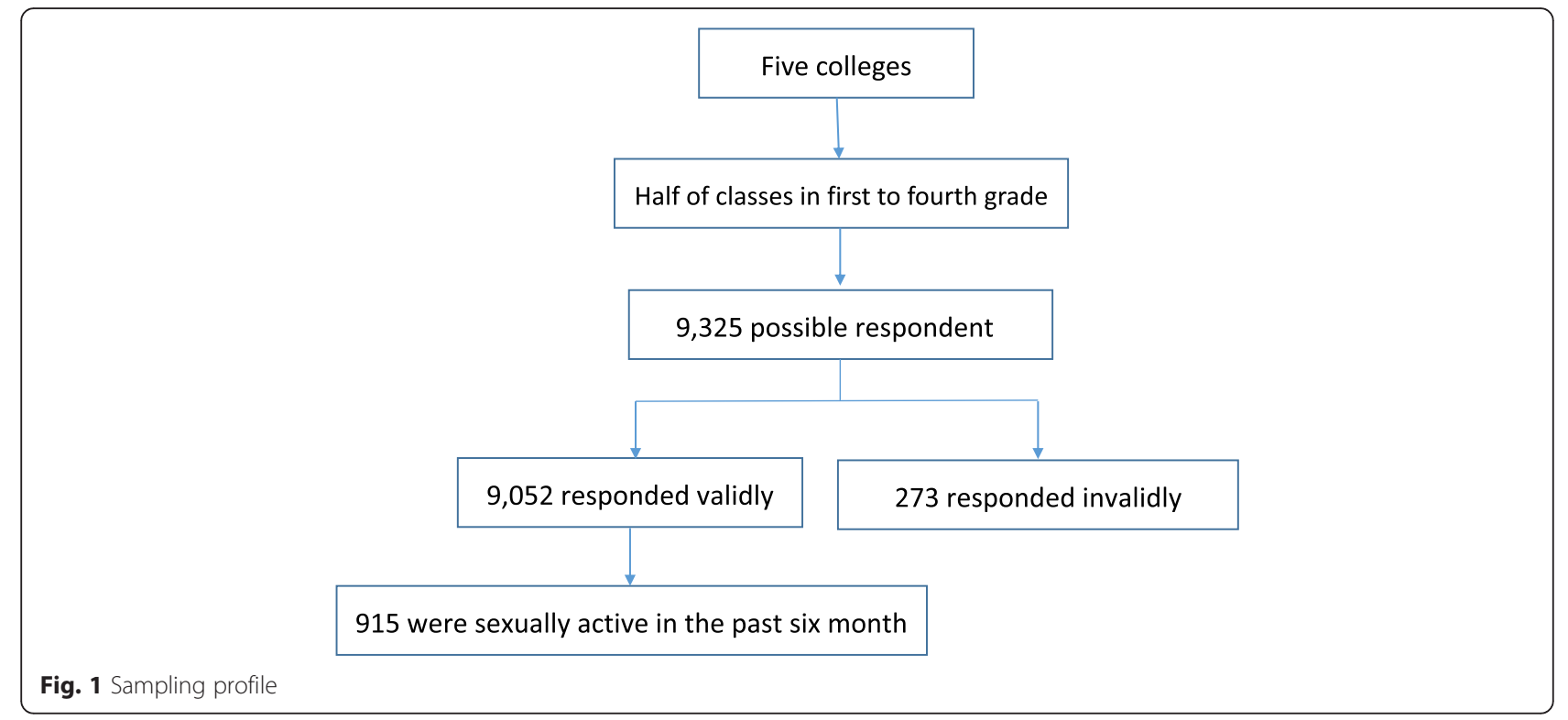

health-related websites were provided at their college. Further, about half of the females in the study reported publications on these topics being provided at the college. Approximately $24 \%$ reported that their college provided contraceptives, and $15 \%$ reported that their college offered birth control counseling. Contraceptive acquisition was reported to be convenient by approximately $13 \%$ of the sample, and less than $10 \%$ of respondents reported that birth control counseling was convenient.

\section{Contraceptive use}

There were six types of contraception with more than $1 \%$ usage (Table 1). Condoms were the most popular form of contraceptive, used by 535 respondents. Oral female contraceptives were the second most popular form of contraception.

\section{Univariate analyses}

As is shown in Tables 2, younger students were less likely to report frequent use of contraception compared with older students. Factors associated with the increased likelihood of frequent use of contraception included the availability of health-related websites at the college, the provision of contraceptives at the college and university student health centers, and convenient access to contraceptives and birth control counseling. The students in casual relationships were less likely to be fully consistent with their contraceptive use than were those in steady relationships. Factors associated with the increase likelihood of being fully consistent with contraceptive use included the provision of healthrelated publications at the college, the provision of birth control counseling at college and university student health centers, and a convenient means of getting contraceptives.

\section{Multivariate analyses}

Table 3 displays the multivariate results from the logistic regression analyses. The multivariate analysis revealed that younger female students had lower odds of contraceptive use than did older students, and students who reported the availability of health-related websites were more likely to use contraceptives than were those who reported that no such websites were available. Contraceptive and birth control counseling provision at the college were associated with greater odds of contraceptive use, and those who reported that college health services were convenient for getting contraceptives and birth control counseling also had greater odds of contraceptive use.

In Model 1, which examines high versus low frequency contraceptive use, six variables entered into the final step. In Model 2, which predicts fully consistent contraceptive (vs. not fully consistent), five variables entered into the final step.

\section{Model 1 (high frequency vs. low frequency)}

We found that students aged under 20 years had a $43 \%$ lower odds of high frequency contraceptive use than that of older students (OR $=0.57,95 \%$ CI: 0.43-0.88). In contrast, young women who reported that health-related websites were provided at their college had a $74 \%$ higher odds of high frequency contraceptive use than that of students reporting that no websites were provided $(\mathrm{OR}=1.74,95 \%$ CI: $1.26-2.42)$. Those respondents reporting that contraceptives were provided at college and university student health centers had a $81 \%$ higher odds than that of respondents reporting that they could not access contraceptives this way of using contraceptives with a high frequency $(\mathrm{OR}=1.81,95 \% \mathrm{CI}$ : 
Table 2 Associations between health services in school and consistency of contraceptive use among female students

\begin{tabular}{|c|c|c|c|c|c|c|}
\hline \multirow[t]{3}{*}{ Characteristic } & \multicolumn{3}{|c|}{ Low vs. High frequency } & \multicolumn{3}{|c|}{ Not fully vs. Fully } \\
\hline & \multirow{2}{*}{$\begin{array}{l}\text { Low } \\
N=245\end{array}$} & \multirow{2}{*}{$\begin{array}{l}\text { High } \\
N=670\end{array}$} & \multirow[t]{2}{*}{$\mathrm{OR}(95 \% \mathrm{Cl})$} & \multirow{2}{*}{$\begin{array}{l}\text { Not fully } \\
N=597\end{array}$} & \multirow{2}{*}{$\begin{array}{l}\text { Fully } \\
N=318\end{array}$} & \multirow[t]{2}{*}{$\mathrm{OR}(95 \% \mathrm{Cl})$} \\
\hline & & & & & & \\
\hline \multicolumn{7}{|c|}{ Individual characteristics } \\
\hline \multicolumn{7}{|l|}{ Age } \\
\hline$<20$ & 40.4 & 31.2 & $0.58(0.41,0.83)^{*}$ & 36.3 & 40.7 & $1.21(0.91,1.61)$ \\
\hline$\geq 20$ & 59.6 & 68.8 & Reference & 63.7 & 59.3 & Reference \\
\hline \multicolumn{7}{|l|}{ Relationship status } \\
\hline casual & 17.4 & 18.9 & $0.94(0.72,2.38)$ & 22.2 & 19.2 & $0.67(0.44,1.00)^{*}$ \\
\hline steady & 72.6 & 71.1 & Reference & 74.6 & 78.5 & Reference \\
\hline \multicolumn{7}{|l|}{ Grade } \\
\hline Senior & 51.4 & 60.3 & $1.18(0.86-1.53)$ & 55.2 & 56.1 & $1.05(0.82-1.59)$ \\
\hline Junior & 48.6 & 39.7 & Reference & 44.8 & 43.9 & Reference \\
\hline \multicolumn{7}{|c|}{ Provision of health related publications } \\
\hline Yes & 51.4 & 58.7 & $1.25(0.86,1.73)$ & 56.9 & 64.6 & $1.38(1.04,1.84)^{*}$ \\
\hline No & 48.6 & 41.3 & Reference & 43.1 & 35.4 & Reference \\
\hline \multicolumn{7}{|c|}{ Availability of designed Web site } \\
\hline Yes & 59.2 & 78.1 & $1.85(1.42,2.56)^{* *}$ & 72.4 & 73.5 & $1.06(0.77,1.45)$ \\
\hline No & 40.8 & 21.9 & Reference & 27.6 & 26.5 & Reference \\
\hline \multicolumn{7}{|l|}{ School education } \\
\hline Yes & 31.3 & 22.6 & $0.76(0.54,1.13)$ & 29.0 & 25.5 & $0.84(0.61,1.15)$ \\
\hline No & 68.7 & 77.4 & Reference & 71.0 & 74.5 & Reference \\
\hline \multicolumn{7}{|c|}{ Provision of contraceptives } \\
\hline Yes & 10.2 & 23.1 & $1.53(1.16,2.76)^{*}$ & 22.5 & 26.2 & $1.22(0.88,1.68)$ \\
\hline No/don't know & 79.8 & 76.9 & Reference & 77.5 & 73.8 & Reference \\
\hline \multicolumn{7}{|c|}{ Provision of birth control counseling } \\
\hline Yes & 11.9 & 16.6 & $1.26(0.89,2.10)$ & 12.7 & 18.5 & $1.57(1.07,2.30)^{*}$ \\
\hline No/don't know & 88.1 & 83.4 & Reference & 87.3 & 81.5 & Reference \\
\hline \multicolumn{7}{|c|}{ Convenient getting contraceptives } \\
\hline Yes & 12.0 & 21.6 & $2.14(1.53,3.28)^{* * *}$ & 9.5 & 16.3 & $2.55(1.55,4.20)^{* * *}$ \\
\hline No & 88.0 & 78.4 & Reference & 90.5 & 83.7 & Reference \\
\hline \multicolumn{7}{|c|}{ Convenient getting birth control counseling } \\
\hline Yes & 8.7 & 16.4 & $2.34(1.49,3.81)^{* * *}$ & 7.6 & 10.6 & $1.43(0.87,2.37)$ \\
\hline No & 91.3 & 83.7 & Reference & 92.4 & 89.4 & Reference \\
\hline
\end{tabular}

1.28-2.82). Additionally, young women who reported convenient means for getting contraceptives and birth control counseling had a 69 and $91 \%$ higher odds, respectively, of high frequency contraceptive use $(\mathrm{OR}=$ $1.69,95 \%$ CI: $1.12-2.64$ and OR $=1.91,95 \%$ CI: $1.21-$ 3.15) than those of young women without convenient access to these things.

\section{Model 2 (fully consistent vs. not fully consistent)}

Young women who reported health-related publications being provided at their college had a $64 \%$ higher odds of fully consistent contraceptive use $(\mathrm{OR}=1.64,95 \% \mathrm{CI}$ : 1.25-2.37). In addition, the odds of fully consistent contraceptive use for those who reported a convenient means for acquiring contraceptives was two times greater than these odds for those who did not $(\mathrm{OR}=2.31$, 95 \% CI: $1.45-3.86)$.

\section{Discussion}

Women can improve their reproductive health outcomes by using contraceptives consistently with sexual partners to prevent unintended pregnancies. A better understanding of 
Table 3 Odds ratios from logistic regression models assessing associations between selected characteristics and contraceptive use

\begin{tabular}{|c|c|c|c|}
\hline Model 1 (low vs. high) & & OR & $95 \% \mathrm{Cl}$ \\
\hline \multirow[t]{2}{*}{ Age } & $<20$ & 0.57 & $(0.43,0.88)^{*}$ \\
\hline & $\geq 20$ & Reference & \\
\hline \multirow[t]{2}{*}{ Availability of designed Web site } & Yes & 1.74 & $(1.26,2.42)^{* *}$ \\
\hline & No & Reference & \\
\hline \multirow[t]{2}{*}{ Provision of contraceptives } & Yes & 1.81 & $(1.28,2.82)^{* *}$ \\
\hline & No & Reference & \\
\hline \multirow[t]{2}{*}{ Convenient getting contraceptives } & Yes & 1.69 & $(1.12,2.64)^{*}$ \\
\hline & No & Reference & \\
\hline \multirow[t]{2}{*}{ Convenient getting birth control counseling } & Yes & 1.91 & $(1.21,3.15)^{*}$ \\
\hline & No & Reference & \\
\hline \multicolumn{4}{|l|}{ Model 2 (Not fully vs. Fully) } \\
\hline \multirow[t]{2}{*}{ Relationship status } & causal & 1.42 & $(0.93,2.21)$ \\
\hline & steady & Reference & \\
\hline \multirow[t]{2}{*}{ Provision of health related publications } & Yes & 1.64 & $(1.25,2.37)^{* *}$ \\
\hline & No & Reference & \\
\hline \multirow[t]{2}{*}{ Provision of birth control counseling } & Yes & 1.37 & $(0.75,1.94)$ \\
\hline & No & Reference & \\
\hline \multirow[t]{2}{*}{ Convenient getting contraceptives } & Yes & 2.31 & $(1.45,3.86)^{* *}$ \\
\hline & No & Reference & \\
\hline
\end{tabular}

${ }^{* * *} p<0.001 ; * * p<0.01 ;{ }^{*} p<0.05$

factors associated with contraceptive use among female students will help college and family to protect student from unintended pregnancy. Many studies have been conducted on contraceptive use among college students, but few of these have focused on health services in Chinese colleges. This study has extended previous research by assessing the associations between the characteristics of college health services at college and contraceptive use and consistency of use. The study also highlighted the need to design a Chinese reproductive health website focusing on young people and covering important information that young people and adolescents need. Our findings also indicate that better contraceptive-related health services play an important role in reducing unintended pregnancies by directly addressing the contraceptive needs of female students.

However, the findings of this study were limited by several factors. The study sample represents a small proportion of female college students in Wuhan. Individuals who did not want to take part in the research may in fact be more affected than those who did participate. Students with more liberal views on sexuality and sexual practices may be more likely to take and complete a sexuality survey; therefore, our results may not be representative of the general student population. Furthermore, the regularity of contraceptive use was not quantified in this study. A further limitation is that the participating students provided information on contraceptive use retrospectively, whereas contraceptive use would ideally be measured using daily calendars. Finally, no cause-effect relationship could be established because of the cross-sectional nature of the study design. Further research is needed to evaluate contraceptive use and examine in more depth how the factors identified in this study affect contraceptive use.

In our study, we found that certain individual characteristics (including younger age and higher socioeconomic status) are associated with a lower frequency of contraceptive use. Similar to our study, a cross-sectional descriptive study conducted across 49 colleges/universities in seven cities of China also found that, when compared with their classmates aged under 20 years, older students were significantly more likely to use contraception [16]. This may be because older female students have a higher level of knowledge and a greater likelihood of discussing sex and contraception with their parents, peers, and partners than do younger students $[3,17]$. However, contraceptive use and consistency has been found to be lower among students older than 35 years [17]. In a univariate analysis, we found that individuals who were in stable sexual relationships were more likely to use contraception in a fully consistent manner, compared with individuals with casual partners, supporting previous studies [18, 19]. However, we did not find any multivariate associations between relationship status and contraceptive use.

We found that the provision of health-related websites by colleges was associated with greater odds of high frequency 
contraceptive use among female students. This is possibly because the Internet may reinforce the importance of communication between partners about sexual risks and contraceptive use [20]. Previous studies showed that websites were a practical and accessible way of delivering sexual health education to young people, capable of improving behaviors associated with sexual activity, such as the frequency of contraceptive use [12, 21, 22]. Some Chinese reproductive health websites focus on couples with infertility or broadly cover family planning and reproductive health knowledge, but few focus on college students or cover the knowledge and information that college students need [7]. Therefore, better designed websites for sex education should be implemented and popularized among college students. In our study, we found an association between the provision of contraceptives and the odds of contraceptive use, supporting findings from previous research [13]. Possibly because contraceptive costs would account for a non-negligible proportion of daily expenses, women in a poor financial situation were found to be less likely to use contraception consistently. In addition, convenient options for buying contraceptives were associated with a higher frequency of contraceptive use in our study. This supports other studies that have shown that the provision of convenient contraceptive services can improve reproductive health outcomes [23, 24]. However, in China, short-acting contraception suitable for people who have no children is mainly provided without cost to married people by the community health center. Therefore, many unmarried young people-especially college students-cannot access and use reliable and free contraception [16].

We also found that contraceptive counseling among individuals at risk for unintended pregnancy was associated with current contraceptive use among female college students, supporting previous research $[25,26]$. School-based contraceptive counselling typically emphasizes unintended pregnancy, sexually-transmitted infections, and other potential risks associated with sex. This type of counseling has a particularly important role in promoting safe sex practices and in preventing multiple unplanned pregnancies and repeat abortions among college students. Our findings indicated that contraceptive counseling may be an important intervention to increase contraceptive use. Additionally, providing free contraceptives at college and university student health centers is associated with increased odds of contraceptive use and consistency of use. China has a strong network of family planning services, with many types of contraceptives provided free of charge. However, family planning services specifically targeting unmarried college students are still absent. Only a few colleges are able to provide free contraceptive services to their students. Efforts should be made to improve contraceptive counseling and services, which would increase the effective use of modern contraceptives [27]. Incorporating this idea into the package of contraceptive services provided at student health centers in colleges could benefit students, and these strategies may help to improve their access to contraceptives [28, 29].

\section{Conclusions}

To prevent negative sexual health outcomes in the college student population, the government must note the importance of sex education among college students, and program efforts must work to instill safe sexual behaviors in this population. Our findings highlighted the need to design a Chinese reproductive health website focusing on young people or covering important information that young people and adolescents need, and to guide young people to visit such a website. Additionally, contraception and birth control counseling are important intervention tools that increase the use of contraception. Better availability of contraceptives plays an important role in reducing the number of unintended pregnancies by directly addressing the contraceptive needs of female students. It is our hope that our findings will guide further interventions and public policy to improve contraceptive availability and reduce unintended pregnancies.

\section{Acknowledgements \\ The authors thank other members for their contribution to this research: Professor Chengliang Xiong(PI), associate Professor Ping Yin, Dr. Min Wang, Ms Chuan Xu. We thank the universities involved in the investigation for their contribution: Huazhong University of science and technology, Jianghan University, Wuhan engineering university, Wuhan University. \\ Funding \\ This study was funded by The National Key Technology R\&D Program (2006BAl15B04), Chengdu Municipal Bureau of Science and Technology(0040405301091) and Sichuan University(2016SCU11007).}

\section{Availability of data and materials}

The datasets during and/or analysed during the current study available from the corresponding author on reasonable request.

\section{Authors' contributions \\ LL participated in the design of this study and drafted the manuscript, SN and SW conceived of the study, YL participated in coordination and performed the statistical analysis, ZC and YS helped to draft the manuscript and performed the statistical analysis. All authors read and approved the final manuscript.}

\section{Competing interests}

The authors declare that they have no competing interests.

\section{Consent for publication}

We obtained written informed consent from all respondents.

\section{Ethics approval and consent to participate}

The researchers obtained consent from all participants involved in the study. The study was approved by the Research Ethics Committee of Tongji Medical College at Huazhong University of Science and Technology in Wuhan, China. We provided detailed information on the study to the eligible college students and included only those who consented to participate. 


\section{Author details}

'West China School of Public Health, Sichuan University, Chengdu, China. ${ }^{2}$ Chengdu Municipal Center for Disease Control and Prevention, Sichuan, China. ${ }^{3}$ Tongji Medical College, Huazhong University of Science and Technology, Wuhan, China.

Received: 31 December 2015 Accepted: 30 August 2016

Published online: 05 September 2016

\section{References}

1. Zhang K, Li D, Li H, Beck EJ. Changing sexual attitudes and behaviour in China: implications for the spread of HIV and other sexually transmitted diseases. AIDS Care. 1999:11(5):581-9.

2. Zhou YZ, Zhang MM, Wei S, Guan HT, Yin P, Ren N, Pang XB, Xiong CL. Survey on knowledge, attitude, practice related to contraception among college students in Beijing. Zhonghua Liu Xing Bing Xue Za Zhi. 2009:30(7):710-2.

3. Ma QQ, Ono-Kihara M, Cong LM, Xu G, Pan X, Zamani S, Ravari SM, Kihara M. Unintended pregnancy and its risk factors among university students in eastern China. Contraception. 2008;77(2):108-13.

4. Zhang D, Bi Y, Maddock JE, Li S. Sexual and reproductive health knowledge among female college students in Wuhan, China. Asia Pac J Public Health. 2010;22(1):118-26

5. Senarath U, Gunawardena NS. Women's autonomy in decision making for health care in South Asia. Asia Pac J Public Health. 2009;21(2):137-43.

6. Morrison LF, Sieving RE, Pettingell SL, Hellerstedt WL, McMorris BJ, Bearinger $\mathrm{LH}$. Protective factors, risk indicators, and contraceptive consistency among college women. Stud Fam plann J Obstet Gynecol Neonatal Nurs. 2016:45(2):155-65.

7. Long L, Yuan T, Wang M, Xu C, Yin J, Xiong C, Wei S, Nie S. Factors associated with condom use among male college students in Wuhan, China. PLoS One. 2012;7(12):e51782

8. Li YF, Gao YH, Chen SX, Lin GZ, Ren YQ. KAP about sex and needs for sex knowledge among middle school students. Chin J Health Educ. 2002;18(5):304-5.

9. Lou CH, Zhao Q, Gao ES, Shah LH. Can the Internet be used effectively to provide sex education to young people in China? J Adolesc Health. 2006;39(5):720-8

10. Phillips KA, Stotland NE, Liang SY, Spetz J, Haas JS, Oren E. Out-of-pocket expenditures for oral contraceptives and number of packs per purchase. $J$ Am Med Womens Assoc. 2004;59(1):36-42.

11. Kavanaugh ML, Jones RK, Finer LB. Perceived and insurance-related barriers to the provision of contraceptive services in U.S. abortion care settings. Womens Health Issues. 2011:21(3 suppl):S26-31.

12. Zhou Y, Xiong J, Li J, Huang S, Shang X, Liu G, Zhang M, Yin P, Wei S, Xiong C. Urgent need for contraceptive education and services in Chinese unmarried undergraduates: a multi-campus survey. J Huazhong Univ Sci Technolog Med Sci. 2011;31(4):426-32.

13. Huang J, Bova C, Fennie KP, Rogers A, Williams AB. Knowledge, attitudes, behaviors, and perceptions of risk related to HIV/AIDS among Chinese university students in Hunan, China. AIDS Patient Care STDS. 2005;19(11):769-77.

14. Tu X, Cui N, Lou C, Gao E. Do family-planning workers in China support provision of sexual and reproductive health services to unmarried young people? Bull World Health Organ. 2004;82(4):274-80.

15. Andersen RM. Revisiting the behavioral model and access to medical care: does it matter? J Health Soc Behav. 1995;36(1):1-10.

16. Zhou Y, Xiong C, Xiong J, Shang X, Liu G, Zhang M, Yin P. A blind area of family planning services in China: unintended pregnancy among unmarried graduate students. BMC Public Health. 2013;6(13):198.

17. Rowen TS, Smith JF, Eisenberg ML, Breyer BN, Drey EA, Shindel AW. Contraceptive usage patterns in North American medical students. Contraception. 2011;83(5):459-65.

18. Ryan S, Franzetta K, Manlove J, Holcombe E. Adolescents' discussions about contraception or STDs with partners before first sex. Perspect Sex Reprod Health. 2007;39(3):149-57.

19. Stone N, Ingham R. Factors affecting British teenagers' contraceptive use at first intercourse: the importance of partner communication. Perspect Sex Reprod Health. 2002;34(4):191-7.

20. Kamal SM. Socioeconomic factors associated with contraceptive use and method choice in urban Slums of Bangladesh. Asia Pac J Public Health. 2011;27(2):2661-76.
21. Goold PC, Ward M, Carlin EM. Can the internet be used to improve sexual health awareness in web-wise young people? J Fam Plann Reprod Health Care. 2003;29(1):28-30.

22. Borzekowski DL, Rickert VI. Adolescent cybersurfing for health information: a new resource that crosses barriers. Arch Pediatr Adolesc Med. 2001;155(7):813-7.

23. Finer LB, Darroch JE, Frost JJ. U.S. agencies providing publicly funded contraceptive services in 1999. Perspect Sex Reprod Health. 2002;34(1):15-24

24. Lindberg LD, Frost JJ, Sten C, Dailard C. The provision and funding of contraceptive services at publicly funded family planning agencies: 19952003. Perspect Sex Reprod Health. 2006;38(1):37-45.

25. Upson K, Reed SD, Prager SW, Schiff MA. Factors associated with contraceptive nonuse among US women ages 35-44 years at risk of unwanted pregnancy. Contraception. 2010;81(5):427-34.

26. Weisman CS, Maccannon DS, Henderson JT, Shortridge E, Orso CL. Contraceptive counseling in managed care: preventing unintended pregnancy in adults. Womens Health Issues. 2002;12(2):79-95.

27. Zeng J, Zou G, Song X, Ling L. Contraceptive practices and induced abortions status among internal migrant women in Guangzhou, China: a cross-sectional study. BMC Public Health. 2015;17(15):552.

28. Hemmick RS, McCarthy SK. Provision of emergency contraceptive pills at college and university student health centers in Florida. J Adolesc Health. 2007:40(1):92-5

29. Kalmuss D, Tatum C. Patterns of men's use of sexual and reproductive health services. Perspect Sex Reprod Health. 2007:39(2):74-81.

\section{Submit your next manuscript to BioMed Central and we will help you at every step:}

- We accept pre-submission inquiries

- Our selector tool helps you to find the most relevant journal

- We provide round the clock customer support

- Convenient online submission

- Thorough peer review

- Inclusion in PubMed and all major indexing services

- Maximum visibility for your research

Submit your manuscript at www.biomedcentral.com/submit
) Biomed Central 